\title{
Article
}

\section{Developing an ecologically relevant heterogeneous biofilm model for dental- unit waterlines}

Lal, Sham, Pearce, Mark, Achilles-Day, Undine EM, Day, John G, Morton, Leslie Hugh Glyn, Crean, Stjohn and Singhrao, Simarjit Kaur

Available at http://clok.uclan.ac.uk/16184/

Lal, Sham, Pearce, Mark, Achilles-Day, Undine EM, Day, John G, Morton, Leslie Hugh Glyn, Crean, Stjohn ORCID: 0000-0001-9336-8549 and Singhrao,

Simarjit Kaur ORCID: 0000-0001-9573-5963 (2016) Developing an ecologically relevant heterogeneous biofilm model for dental-unit waterlines. Biofouling, 33 (1). pp. 75-87. ISSN 0892-7014

It is advisable to refer to the publisher's version if you intend to cite from the work. http://dx.doi.org/10.1080/08927014.2016.1260710

For more information about UCLan's research in this area go to

http://www.uclan.ac.uk/researchgroups/ and search for <name of research Group>.

For information about Research generally at UCLan please go to http://www.uclan.ac.uk/research/

All outputs in CLoK are protected by Intellectual Property Rights law, including Copyright law. Copyright, IPR and Moral Rights for the works on this site are retained by the individual authors and/or other copyright owners. Terms and conditions for use of this material are defined in the policies page.

\section{CLoK}

Central Lancashire online Knowledge www.clok.uclan.ac.uk

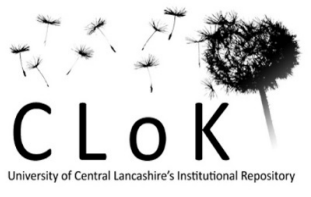


Title: Developing an ecologically relevant heterogeneous biofilm model for dental-unit waterlines

Journal name: Biofouling

Authors: Sham Lal ${ }^{1,2}$, Mark Pearce ${ }^{1}$, Undine E.M. Achilles-Day ${ }^{3}$, John G. Day ${ }^{4}$, L. H. Glyn Morton ${ }^{1}$, ${\text { StJohn } \text { Crean }^{1}, \text { Sim K. Singhrao }}^{1 *}$,

$\underline{{ }^{1} \text { Oral \& Dental Sciences Research Group, }}$

College of Clinical and Biomedical Sciences,

$\underline{\text { University of Central Lancashire, }}$

Preston, PR1 2HE, UK.

${ }^{2}$ Department of Microbiology,

Shah Abdul Latif University, Khairpur, Pakistan.

${ }^{3}$ Department of Life \& Environmental Science,

Bournemouth University, Talbot Campus, Fern Barrow, Poole, BH12 5BB, UK.

${ }^{4}$ Culture Collection of Algae and Protozoa,

The Scottish Association for Marine Science (SAMS), Oban, PA37 1QA, UK.

$\underline{\text { Running Title: Dental-unit waterline biofilm model }}$ 


\begin{abstract}
:
This study monitored the biodiversity of microbes cultured from a heterogeneous biofilm which had formed on the lumen of a section of dental waterline tubing over a period of 910 days. By day two bacterial counts on the outlet-water showed that contamination of the system had occurred. After 14 days, a biofilm comparable to that of clinical waterlines, consisting of bacteria, fungi and amoebae had formed. This showed that the proprietary silver coating applied to the lumenal surface of the commercial waterline tubing failed to prevent biofilm formation. Molecular barcoding of isolated culturable microorganisms showed some degree of the diversity of taxa in the biofilm, including the opportunistic pathogen Legionella pneumophila. Whilst the system used for isolation and identification of contaminating microorganisms may underestimate the diversity of organisms in the biofilm, their similarity to those found in the clinical environment makes this a promising test-bed for future biocide testing.
\end{abstract}

Key words: Biofilm, simulated waterline system, Legionella pneumophila 


\section{Introduction}

In the UK, as in most developed countries, there is often a common water supply from reservoirs to

domestic, public and commercial users. These reservoirs may contain low numbers of human opportunistic bacteria such as Legionella pneumophila

(http://www.epa.gov/ogwdw/disinfection/tcr/pdfs/whitepaper_tcr biofilms.pdf). In the distribution systems, pipes (dead legs/blind ends) and infrequently used water taps can provide a niche where L. pneumophila may thrive and multiply within amoebae that graze on bacteria (Tyndall \& Dominigue 1982; Rowbotham 1986; Barbaree et al. 1986; Wadowsky et al. 1991). Although legionellosis was first identified in an outbreak in Philadelphia in the USA in 1976 (Fraser et al. 1977), it is now known that there have been a significant number of public outbreaks due to the presence of L. pneumophila in water systems worldwide. Furthermore, recreational and healthcare services are vulnerable to such outbreaks and need to be monitored frequently.

All surgeries depend on dental-unit waterlines to supply water to hand-pieces of dental drills during clinical treatment. These waterlines are a complex system of thin pipes and valves that supply clean water from a reservoir to the drill for the cooling of oral tissues undergoing treatment. In-between treatments, the water within the tubing may become "stagnant" and this allows the development of a microbial biofilm (Blake 1963). The contamination of water by planktonic heterotrophic bacteria is normally assessed by culture methods on R2A agar plates (Reasoner \& Geldreich 1979; 1985). However, currently, there is no guidance on the frequency of monitoring treatment water.

It is considered normal practice for waterlines undergoing treatment using biocides (Williams et al. 1994) to follow the protocol recommended by their manufacturer, usually on daily basis, to prevent contamination. However, few practices have the resources, or expertise, to undertake routine assessments of the efficacy of the treatments. In a recent study (Lal 2016), where assessments were systematically performed, $52 \%$ of the dental surgeries tested, failed to meet the standards set by the authorities i.e. that water discharged from a dental-unit should be at least as clean as that from the domestic water. The reasons 
for this are not fully understood, but it has been speculated that when used in the clinical environment, biocides may result in incomplete control (Costa et al. 2016).

Comprehensive lists of contaminating microorganisms isolated from dental-unit waterlines are described elsewhere (Pankhurst et al. 1998; Szymanska et al. 2008; Kumar et al. 2010) and although the majority of waterborne bacteria pose no risk of infection, opportunistic nosocomial pathogens from dental waterlines have been associated with human cases of infection including L. pneumophila, non-tuberculosis Mycobacterium spp., Klebsiella pneumoniae and Pseudomonas aeruginosa (Martin 1987; Pankhurst et al. 1998; D’Ovidio et al. 2011; Ricci et al. 2012).

Amoebae also reside in the waterline biofilm and feed on mixed communities of bacteria (Michel \& Just 1984; Barbeau \& Buhler 2001; Dillon et al. 2014 ). L. pneumophila, ingested by amoebae, not only $\underline{\text { survive, but remain resistant to recommended biocidal disinfection regimes used to clean the waterlines }}$ (Dillon et al. 2014 $)$. Legionella can then survive within the amoebal cell vacuoles where they are protected from biocides and multiply. Once released from the amoebal cells L. pneumophila will become re-suspended in the water, and along with other biofilm bacteria contaminate the water within the dental-unit and $\underline{\text { subsequently the surrounding environment via aerosol sprays. Such a scenario can lead to the potential }}$ infection of patients and dental professionals.

In the UK, primary dental care premises are required to comply with the Health and Safety at work acts $(1974,1999)$ http://www.healthyworkinglives.com/advice/Legislation-and-policy/Workplace-Healthand-Safety/health-safety-legislation, and the Environment Agency water maintenance regulations 1999 , $2001 \mathrm{http}: / /$ www.hse.gov.uk/aboutus/howwework/framework/aa/hse-ea-nov12.pdf. These provide guidance for control of L. pneumophila (ACOP 18) www.hse.gov.uk/legionnaires/what-you-must-do.htm, which includes the Department of Health, UK, recommendations for undertaking a written Legionella risk assessment of hot air and cold water plumbing by a competent and a qualified water engineer from the Legionella Control Association. The assessment should identify and assess sources of known risk for the growth of Legionellae. Failure to comply can result in a criminal prosecution. In the USA, the Centers for

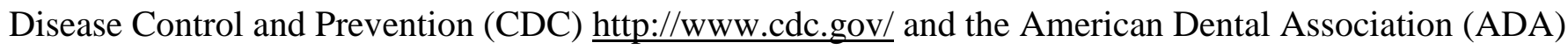


recommend that the microbial load of the discharged water should be below 500 colony forming units (CFU) of aerobic mesophilic heterotrophic bacteria/millilitre (CFU ml ${ }^{-1}$ ) (Kohn et al. 2003). The recommended standards for dentistry set by the Department of Health, in the UK, HTM 01-05 are of $\leq 200$ CFU ml ${ }^{-1}$ (Anon 1993; Anon 1996; Al Shorman et al. 2002; Kohn et al. 2003; ADA 2004; http://www.cdc.gov/;HTM 01-05: http://www.dh.gov.uk).

In 2012, Ricci and co-workers reported the death of an elderly Italian female from Legionnaires’ disease following inhalation of aerosols during dental treatment. In order to confirm this claim, tap water $\underline{\text { samples were taken from the sink of the dental surgery, and from the high-speed turbine of the dental-unit }}$ waterlines, as well as water from the deceased patient's home (tap and shower) for laboratory analysis for the presence of L. pneumophila. Subsequently, the same strain of L. pneumophila as the one isolated from the patient ${ }_{2}$ was found in tap water and the dental-unit waterlines output water in the dental practice (Ricci et al. 2012).

In vitro simulated waterline system $\underline{\underline{s}}$ have been $\underline{\text { used to }}$ test proprietary biocides for dental use (Spratt et al. 2004; Dillon et al. 2014 ; Lal et al. 2015; Ditommaso et al. 2016). These in vitro model $\underline{\underline{s}}$ were designed primarily for testing biocide efficacy on specific biofilm bacterial species (Spratt et al. 2004) and on Vermamoeba vermiformis (Dillon et al. 2014 ). The latter model was used for subsequent studies on the cultivation of amoebae for in vitro propagation of an avirulent form of Legionella (Dillon et al. 2014 ${ }^{\mathrm{b}}$ ), and Serratia marcescens (Lal et al. 2015). More recently, Ditommaso et al. (2016) tested the efficacy of a biocide on $L$. pneumophila serogroup 1 in a new clinical dental waterline without an ecologically relevant biofilm.

The rationale for this study was to establish an ecologically relevant heterogeneous biofilm model $_{2} \underline{\text { in }}$ which naturally occurring Legionella species could be detected to replicate a clinical waterline system. It was also an objective of the study to develop a model that truly represented a clinical environment that could in future be used as a test-bed for biocide studies. 


\section{Biofilm formation in dental-unit waterline tubing}

Following ethical approval, a simulated in-vitro waterline system, based on former designs (Spratt et al. 2004; Dillon et al. 2014 a), was set up to allow natural biofilm formation from the microbes in tap water. The model consisted of a plastic container (Fisher Scientific) with a total liquid capacity of 5 litres, to which a length of approximately 2 metres of dental waterline tubing with a 4 millimetre bore was attached (courtesy of A-dec, Dental UK Ltd). A peristaltic pump (HaiYang, China) was connected to the tubing to supply a constant flow rate of the water at $6 \mathrm{~L} \mathrm{~h}^{-1}$ (Figure 1). The water supply was taken from a header-tank and the water was free of any known additives, other than conforming to compliance of water enforced by Health and Safety at work acts in the UK $(1974,1999)$ and water maintenance regulations 1999 and guidance for control of L. pneumophila (ACOP 18). During normal working days (Monday to Friday), fresh cold, tap water circulated through the reservoir by a peristaltic pump, filling the container up to the $3 \underline{\mathrm{L}}$ mark to match the output flow rate. Overnight and at the weekends, water from the reservoir was circulated continuously

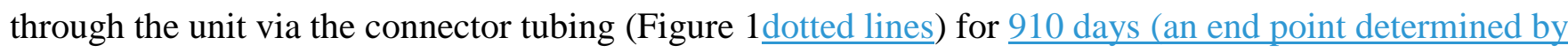
presence of planktonic L. pneumophila).

\section{Establishment of biofilm microbes in the waterline system}

To enumerate planktonic bacterial levels, samples of the tap water and the output water for CFU counts from simulated waterline as indicated in Figure 1, were collected in a sterile container first thing each morning for 14 days and thereafter once a week for total of 180 days. Using a class II safety cabinet serial dilutions were prepared down to $10^{-7}$ in sterile containers and mixed manually by vigorous shaking. An aliquot $(0.1 \mathrm{~mL})$ of the diluted planktonic suspension and the tap water (control) was inoculated (in triplicate), onto freshly poured, pre-labelled R2A agar plates (Lab M). The neat water samples were also inoculated on Glycine-VancomycinPolymyxin-Cycloheximide (GVPC) medium plates (Fisher Scientific) for the detection of Legionella spp on days 1 to 14 and thereafter once a week for up to 180 days and thereafter at $\sim 120$ day intervals up to the end of the study (910 days). The GVPC plates were incubated at $30^{\circ} \mathrm{C}$ in a humid environment for up to 7 days. 
All R2A agar plates were incubated at $22^{\circ} \mathrm{C}$ for 7 days. Following incubation the plates with colonies in the range of 30-300 were counted and the $\mathrm{CFU} \mathrm{m}{ }^{-1}$ calculated using the mean of the triplicate $\mathrm{R} 2 \mathrm{~A}$ plate readings and adjusted for the dilution factor.

\section{Detection of culturable microorganisms from the biofilm community}

A length of the reservoir-DUWL tubing $(1 \mathrm{~cm})$ from the water outflow section (Figure 1) was removed and, in a class II safety cabinet and cut lengthwise to expose the lumen. The biofilm growing on the wall of the lumen of one half of the tube was swabbed (polypropylene swab tube plastic stick) on days $2,3,5,6,13,14$ and then again on days 180 and 910. The attached microbes were then dispersed in $2 \mathrm{~mL}$ of sterile water and serial dilutions were prepared and inoculated on R2A agar plates, as outlined above.

Measurement of chemical and physical parameters

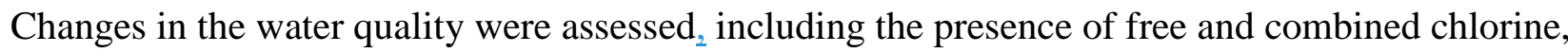
temperature and $\mathrm{pH}$. The concentration of free and combined chlorine was measured using CHECKIT $^{\circledR}$ Comparator Chlorine kit (Fisher Scientific, UK) on-site for 84 days. Temperature and pH were measured using a thermometer and a pH-meter (340i WTW, Weilheim, Germany).

\section{Liveldead cell assay}

A routinely employed Propidium Iodide (PI) uptake assay to assess biocide activity protocol (Dennison et al. 2009) was adapted to estimate the dead bacterial cells using microscopy. A length (1 mm) of the reservoir-

DUWL tubing from the water outflow section of the tubing was removed (Figure 1), from which, a loop full of the biofilm was taken and spread onto glass slides. One of the slides was treated with $10 \%$ buffered formalin for 5 minutes followed by a PBS wash. These and the test smears (without formalin treatment, in triplicate) were all mounted under glass coverslips using the Vectashield® PI mounting medium (Vector laboratories, Peterborough, UK). To visualise any auto-fluorescing bacteria under the microscope, an initial biofilm smear was also mounted under glycerol/PBS in 9:1 ratio. Images were captured using the 510 series Zeiss confocal microscope (Carl Zeiss Ltd). The bacterial cells having taken up PI were estimated from recorded images and related to the total viable count (TVC)/1 mm tube section. 
Total viable counts

$\underline{\text { To calculate TVC from the remaining biofilm on the tube }(1 \mathrm{~mm}) \text { section, bacteria were dispersed in } 1 \mathrm{~mL}}$

of sterile water and serial dilutions prepared. An aliquot $(100 \mu \mathrm{l})$ of the appropriate dilution was then

inoculated onto R2A agar plates and incubated as described earlier.

\section{Opportunistic Bacteria}

Detection of potential opportunistic, human pathogens from the tubing involved inoculation of a non-diluted biofilm suspension $(0.1 \mathrm{~mL})$ on Pseudomonas isolation agar (Sigma) plates; HiCrome ${ }^{\mathrm{TM}}$ Klebsiella selective medium (Sigma) and GVPC plates on days 2, 3, 5, 6, 13, 14, day 180 and then periodically up to day 910. The GVPC plates were incubated as described above and Pseudomonas isolation agar, the HiCrome ${ }^{\mathrm{TM}}$

Klebsiella selective medium plates incubated at $37^{\circ} \mathrm{C}$ for 2 days.

\section{Fungi}

For the isolation of fungi, an additional aliquot $(0.1 \mathrm{~mL})$ of the undiluted biofilm suspension was used to inoculate malt extract agar plates ( $\mathrm{Lab} \mathrm{M})$ with the addition of chloramphenicol $\left(0.1 \mathrm{~g} \mathrm{~L}^{-1}\right)$. The plates were then incubated at $22^{\circ} \mathrm{C}$ for 7 days.

\section{Protozoa}

For isolating protozoa, freshly prepared Escherichia coli (XL blue) were used to serve as a "food line" (Lal et al. 2015). The unused half of the cut side of the tubing was placed directly in contact with one end of the food line to "encourage" amoebae to graze on E._coli supplied as food on the R2A plate then incubated at $22^{\circ} \mathrm{C}$ for 7 days.

\section{Sub-cultures and maintenance}

Bacteria from $R 2 A$

Selected isolates (based on morphological characteristics) of the colonies growing on the R2A plates, were $\underline{\text { sub cultured onto fresh R2A plates and incubated as described earlier. }}$ 
Bacteria from GVPC plates to R2A plates

Selected colonies growing on the GVPC plates, were also sub cultured onto fresh R2A plates and incubated as before. This was performed in order to eliminate non- Legionella colonies that may have been growing on GVPC plates and to show if they demonstrated pigment and/or swarming characteristics on R2A.

\section{Maintenance of fungi}

Blackish green - coloured colonies were isolated on the malt extract agar plates containing chloramphenicol. For subsequent microscopic identification, a pure culture of each colony type from each plate was obtained and maintained by sub-culturing onto new malt extract agar plates without chloramphenicol as before.

\section{Molecular identification of isolated bacteria}

Samples of bacteria were collected from the biofilm growth from the tubing lumen on days $2,3,5,6,13,14$, from R2A plates and then from Pseudomonas isolation agar, the HiCrome ${ }^{\mathrm{TM}}$ Klebsiella selective medium plates incubated at $37^{\circ} \mathrm{C}$ for 2 days and the GVPC plates for human pathogenic bacterial species at 180 and

at 910 days. Colonies were "picked" and genomic DNA isolated from cells lysed in $20 \mathrm{mg} \mathrm{ml}^{-1}$ lysozyme in buffer (20 mM Tris-HCl pH 8.0, 2 mM EDTA, 1.2\% Triton X-100). A Qiagen DNA easy blood \& tissue kit 69504 was used (as per manufactures' instructions) to isolate and purify DNA. The purified DNA pellets were re-suspended in $50 \mu \mathrm{L}$ of AE buffer (from kit) and quantified using a Nanodrop 1000 spectrophotometer. DNA amplification was performed as detailed by Paster et al. (2001) using the universal 16S rRNA bacterial gene primers D88F and E94R. The positive control consisted of all reagents and DNA isolated from a lab culture of $P_{2}$ aeruginosa and the negative control included all reagents except for the test genomic DNA. Presence of PCR products was confirmed using $1 \%$ agarose gel electrophoresis using standard conditions. Sequencing was performed using the BigDye ${ }^{\circledR}$ Terminator v3.1 cycle sequencing kit on an ABI system and assembly of the data was carried out using Geneious Pro v6.1.5

(http://www.geneious.com/). The assembled sequences were submitted to the NCBI Basic Local Alignment Search Tool (GenBank) and incorporated in the Silva comprehensive ribosomal RNA databases to find the identity of the organisms. Only those sequences with > 200 bases and 98-100\% alignment were considered for the identity of the organism (Stackebrandt \& Goebel 1994). 


\section{Tentative identification of the isolated fung $\underline{\underline{u S}}$}

The isolated fungal colonies were tentatively identified by macroscopic and microscopic methods, according to the morphological characteristics of their hyphae and fruiting bodies (Onions et al. 1991). Using aseptic technique, small samples of mature peripheral fungal growth were removed from colonies growing on plates of malt extract agar and placed onto glass microscope slides for examination under phase-contrast and differential interference contrast microscopy (DIC).

\section{Molecular identification of protozoa}

Amoebae from a culture plate were removed using $5 \mathrm{ml}$ of sterile distilled water and collected prior to centrifugation for $3 \mathrm{~min}$ at $25004 \times \mathrm{g}$. The supernatant was discarded and the cell pellet retained for molecular profiling. Genomic DNA was extracted from the cell pellet using the DNeasy Plant Mini kit, according to the manufacturer's instructions. DNA amplification and sequencing for ribosomal RNA gene was performed using the QIAGEN Taq PCR Master Mix using EAF3 and ITS055R as PCR primers (Marin et al. 2003). For the amplification in the thermo-cycler the following protocol was used: an initial denaturation step at $95^{\circ} \mathrm{C}$ for 2 minutes was followed by 30 cycles including denaturation $\left(95^{\circ} \mathrm{C}\right.$ for 1 minute), annealing $\left(55^{\circ} \mathrm{C}\right.$ for 2 minutes), and elongation $\left(68^{\circ} \mathrm{C}\right.$ for 3 minutes). The amplified product was visualised using electrophoresis (1.5\% agarose gel) and purified using QIAquick PCR Purification Kit, following manufacturer's instructions. Sequencing was performed on an ABI system and data analysed as detailed above for bacteria.

\section{Morphological analysis of the microbial communities from the biofilm}

\section{Scanning electron microscopy of tubing.}

Scanning electron microscopy (SEM) of a section of unused, new and used in-vitro simulated waterline tubing (A-dec, Dental UK Ltd.) was performed to visualize the luminal surface before and after formation of a biofilm from the initiation to the end of this study spanning 910 days. The first examination was on material from day one to day 14 and samples were then examined at 84 days, 180 days and 910 days. Tubing 
sections (1-cm length) were removed and split lengthwise prior to their immersion in $2.5 \%$ glutaraldehyde solution (Agar Scientific) in phosphate-buffered saline (PBS) for $3 \mathrm{~h}$ at $4^{\circ} \mathrm{C}$. Following an overnight wash in PBS, all specimens were further processed as described previously (Dillon et al. 2014 ${ }^{\mathrm{a}}$ ).

Transmission electron microscopy to visualise Legionellae inside amoebae from mature biofilm.

A $1 \mathrm{~cm}$ cut end of the tubing by day 910 (see figure 1) was directly immersed into $2.5 \%$ glutaraldehyde

fixative for up to $3 \mathrm{~h}$ at $4^{\circ} \mathrm{C}$. Following washes in PBS, the tubing section was processed to full dehydration in a series of graded ethanol (70\% to $100 \%)$. During the dehydration steps, the intact biofilm from the lumen of the tubing -detached free of the plastic. From thereon, the intact biofilm alone was processed and embedded in Araldite as described previously (Dillon et al. 2014 ${ }^{\mathrm{a}}$ ). The TEM images of amoebae were taken directly from the biofilm from the day 910 time point.

\section{Statistical analysis}

All analyses were performed using the Minitab 16 statistical software. Where appropriate, data are presented as the mean $\pm \mathrm{SD}(\mathrm{N}=3)$, tested for normality and equal variances, analysed by a $t$-test for two independent samples and Pearson correlation coefficient. Differences were considered significant at $p \leq 0.05$.

\section{Results}

\section{Time span for the biofilm formation}

The simulated waterline system (Figure 1) used the same quality waterline tubing (A-dec Dental UK Ltd, http://gb.a-dec.com/en/) as is incorporated into commercial dental chair units. The planktonic bacterial counts from the in-vitro simulated waterlines output water and the Anderson-Darling normality test (Minitab 16) suggested the data were normally distributed, and the independent samples $t$-test demonstrated a statistically significant result $(p=0.0001)$ for test water compared to the tap water used as control (Figure 2A) by day two. 


\section{Longer-term monitoring of output water}

After 15 days, as the biofilm established, the bacterial cell counts initially remained high until day 57,

fluctuating between one and $\sim 10$ million CFU ml ${ }^{-1}$ and then dropped to $\sim 10,000 \mathrm{CFU} \mathrm{ml}^{-1}$ (Figure $2 \mathrm{~B}$ ). The degree of linear dependence between $\mathrm{CFU} \mathrm{m} \mathrm{m}^{-1}$ count of test and control water samples was calculated using the correlation coefficient test on normally (Anderson-Darling) distributed data. The results indicated a negative correlation between fluctuation in the numbers of bacteria from simulated waterlines output water and tap water samples $(r=-0.079 ; p=0.402)$ (Figure 2B).

\section{Legionella spp. from discharged water at 910 days}

Enumeration of the discharged water from the laboratory model of the waterline tubing for human

pathogenic bacterial species on GVPC plates at 910 days was $1,620 \mathrm{CFU} \mathrm{ml}^{-1}$ (Figure 2C-A). They were

Gram negative rods and did not grow on R2A agar upon sub-culturing.

\section{Measurement of chemical and physical parameters}

Free chlorine was not detected in the tap water tested once every seven days up to 183 days, indicating potentially inadequate disinfection of the tap water supply. Over this period, the $\mathrm{pH}$ of the tap water source ranged from 6.71 to 7.69 and in the simulated waterlines reservoir between $\mathrm{pH} 6.98$ to 7.8 . The tap water temperature varied between $18-25^{\circ} \mathrm{C}$ and was between $19-26^{\circ} \mathrm{C}$ in the simulated waterlines reservoir water.

\section{Live/dead assay}

Under the confocal microscope, the intact bacterial smear demonstrated little auto-fluorescence (Figure 2C$\underline{A}$ ), whereas the bacterial cells treated with formalin fluoresced red (Figure 2C-B). In the test biofilm smear both red fluorescing cells and non-fluorescing cells were observed (Figure $2 \mathrm{C}-\underline{\mathrm{C}}$ ). On enumeration of cells which had taken up PI in the test smears, around $1.1 \times 10^{3}$ cells fluoresced red field ${ }^{-1}$. The TVC from the remaining biofilm on the tube section gave a viability count of $2.1 \times 10^{7} \mathrm{CFU} \mathrm{mm}^{-1}$. 
Five bacterial colonisers were isolated in the first 14 days and of these, three were Gram negative rods, one was Gram variable rod and one was a Gram positive coccus. The molecular identities of the bacterial species isolated from simulated waterlines were: Acidovorax facilis, Leptothrix cholodnii which survived only a few subculture transfers, Mycobacterium chelonae strain B14, Herminiimonas saxobsidens and Micrococcus luteus. One bacterial coloniser isolated after 910 days of biofilm establishment was L. pneumophila. Neither P. aeruginosa nor Klebsiella spp., were recovered using microbiological culture methods during this study. The amoeba was identified as $V_{-}$vermiformis, as published elsewhere (Dillon et al. 2014 a). On the R2A culture plates, A. facilis and, H. saxobsidens demonstrated their swarming characteristics with A. facilis spreading the faster of the two. H. saxobsidens were unable to swarm when transferred onto plates of GVPC medium.

\section{Tentative identification of a fung $\underline{u s}$}

Macroscopically, the colonial texture was velvety and became powdery overtime. The surface colonial colour was blackish green while on the reverse side it was black. Microscopically, both hyphae and conidiophore were septate and dark in colour. Conidiophores produced branching acropetal chains of unicellular and smooth conidia (Not shown). All the aforementioned features of the isolate agreed with the features of Cladosporium cladosporioides (Onions et al. 1991).

\section{Morphological analysis of the microbial community}

SEM evidence of microbial biofilm ecology within the simulated waterlines tubing

SEM examination of the overview of sections of the lumen of the experimental tubing before use, demonstrated a rough coating on the luminal surface (Figure $\underline{3} \mathrm{~A}$ ). On day one, no biological growth was observed, but from day two to five, a few bacterial colonies adhering to the rough luminal coating were

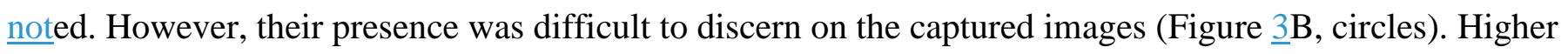
confluency of microbial growth was observed after 14 days (Figure $\underline{3}$ C), with evenly distributed microbial growth observed after $\underline{84 \text { days }}$ (Figure $\underline{3 D}$ ) and an encrusted layer of mature biofilm after 180 days (Figure 
4E) and 910 days (Figure $\underline{3}$ F). At higher magnification, SEM images (Figure 4 ), confirmed the presence of microbial colonisers in the simulated waterlines biofilm in the order as follows: on day 1 antimicrobial coating alone (Figure $\underline{4} \mathrm{~A}$ ); on days $\underline{2-5}$ rod shaped bacteria (Figure $\underline{4} \mathrm{~B}$ red box); $\underline{\text { on day }} \underline{6}$ cocci and rods (Figure $\underline{4}$ ). Also by day $\underline{6}$, cocci and rods were observed to be within an extracellular, assumed polysaccharide matrix (Figure $\underline{4 D}$ ); at day $\underline{8}$ spiral shaped bacteria or possibly Actinomycete spores (Figure $\underline{4 E}$, arrow and insert E1); by day $\underline{9}$ longer bacterial rods in extracellular matrix (Figure $\underline{4 F}$ ); after $\underline{84}$ days longer spiral shaped bacteria (Figure $\underline{4} \mathrm{G}$ arrow), fungal hyphae amongst a cluster of cocci (Figure $\underline{4} \mathrm{H}$ rectangular box) and amoebae (Figure $\underline{4}$ I, square box) were observed.

Transmission electron microscopy to visualise Legionellae inside amoebae from mature biofilm at days 910 Having isolated a potential human pathogen such as L. pneumophila in the simulated waterlines, it was considered appropriate to check whether the $V$. vermiformis sharing the same niche, were supporting their life-cycle. TEM images taken directly from the biofilm itself from day 910, demonstrated the typical healthy, nucleated trophozoite form of $V$. vermiformis with hyaloplasm around the periphery and food vacuoles containing fully digested debris (Figure $\underline{5} \mathrm{~A}, \mathrm{~B}$ ), without any evidence of harbouring vast numbers of metabolically viable bacteria in their food vacuoles and/or in the cytoplasm.

\section{Discussion}

The biofilm grown under laboratory conditions in simulated polyurethane waterline tubing aimed to replicate a clinical scenario without biocide control to determine the possibility of detecting L. pneumophila. A heterogeneous biofilm initiated and developed within 14 days from start of the experiment. This biofilm was made up of Gram negative bacteria both rods and cocci, in an extracellular matrix and included at least one fungal and one amoeba species. The organisms detected and identified, via isolation and cultivation in pure culture, were comparable to previous reports on the diversity of culturable microorganisms isolated

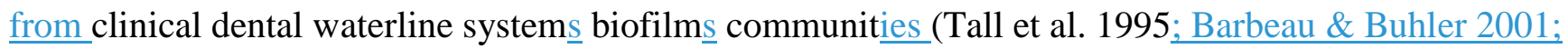


Dillon et al. 2014; Kadaifciler \& Cotuk 2014). The bacterial counts on the outlet water from the simulated waterlines demonstrated contamination had occurred by day two. Over the duration of the study a more diverse and complex microbial consortium developed with additional microbial species co-habiting the same niche. By day 910 detection of the human opportunistic pathogen, L. pneumophila determined the end point of the study. It could be considered that if an enrichment protocol, such as that suggested by Atlas et al. (1995) had been followed, then the detection of L. pneumophila may have been accomplished sooner and the duration of study could have been reduced.

In this study, the rationale for sub-culturing all colonies that were initially observed on GVPC plates was to determine whether they were Legionella, as a variety of non-Legionella species with glassy appearance, a typical example $S$. marcescens, can also grow on this medium (Lal et al. 2015). By culturing bacteria on R2A, the isolated bacteria may demonstrate their pigmentation and swarming characteristics.

In order to measure the degree of linear dependence between simulated waterlines output water and tap water samples, correlation coefficient test (Minitab 16) was performed ${ }_{2}$ which demonstrated a negative correlation between fluctuations in a number of bacteria from both samples $(r=-0.079 ; p=0.402)$. A similar result was previously reported by Tall et al. (1995) following the establishment of a biofilm in their clinical waterline system, but without further explanation for this occurrence. The negative correlation in the present study may be due to several factors including the observation that free chlorine was not detected in the tap water. This indicated insufficient quantities of disinfectant were being applied to ensure control of water contamination at source. In addition, in the present study, the water temperature in the simulated waterline was consistently $1^{\circ} \mathrm{C}$ higher than the source tap water. Seasonal variation in temperature are widely known to influence bacterial counts of water (van der Kooij 1992), therefore the constantly warmer simulated waterline environment will almost certainly have encouraged microbial growth and dispersion. By far the most significant factor contributing to the negative correlation observed in CFU count may be the proportion of non-culturable but viable organisms and the dead cells embedded within the deeper biofilm layers. This was further explored by using the PI live/dead cell assay, adapted from an accepted protocol in which biocide efficacy was being estimated (Dennison et al. 2009). Discrepancies between the planktonic bacterial count and observation $\underline{s}$ by SEM of a thicker biofilm were in part explained by the observation of 
large numbers of dead cells on lumen of tube. The authors acknowledge the limitation of this approach, as only those bacteria with damaged cell surface membrane would have taken up PI, but not necessarily dead cells that were embedded within the deeper layers of extracellular matrix.

In the biofilm in this study A. facilis, formerly known as Pseudomonas facilis (Rittenhouse et al. 1973), was the first organism isolated from the lumen of the waterline. Morphological features documented previously by Kilb et al. (2003) suggests that $A$. facilis is a common water contaminant due its ability to swarm (spread), colonise, and flourish rapidly in a mineral medium with or without any organic matter (Palleroni 1989). This suggests either A. facilis is able to grow chemolithotrophically, or the polyurethane plastic tubing components were leaching out as a supply of nutrients supporting its survival and proliferation (Nakajima-Kambe et al. 1995). The next colonizer in the one to 14 days was the Gram negative L. cholodnii, $a$ filamentous, sheathed, bacterium that can form globules of poly-hydroxybutyrate in their cytoplasm as a food reserve. This enables L. cholodnii to survive in nutrient-poor environments (Furutani et al. 2012), and is highly adaptable to conditions conducive to maintaining biofilm progression.

Mycobacterium chelonae was the third coloniser that was successfully cultivated from the simulated waterline tubing. This organisms has Gram variable characteristics and is one of the faster growing Mycobacterium species that form biofilms under low and high nutrient conditions (Hall-Stoodley et al. 1998). In contrast the genus Herminiimonas is a relatively newly described tax on (Fernandes et al. 2005) to which H. saxobsidens has been included as a member (Lang et al. 2007). Pathogenic L. pneumophila was also isolated from the polyurethane simulated waterline tubing, when the biofilm had become fully established and matured over time (910 days). All of these bacterial isolates (except for the Legionella species), demonstrated at least one pilus, a strategic factor that promotes attachment of bacteria to their biofilm substrates so that they can withstand shear forces and obtain nutrients (Proft \& Baker 2009). These colonisers also contributed to laying down the polysaccharide extracellular matrix ${ }_{2}$ which allows bacterial cells to become scattered within its channels gaining extra surface area to volume ratio for biofilm growth, and protection against desiccation and toxic substances (Donlan \& Costerton 2002). This could be another reason why the dental biocides fail to control the waterline biofilm and indicates the importance of a unified model test-bed for biocide testing. 
Embedded within the polysaccharide extracellular matrix were a variety of spiral shaped Actinomycetes species, known for their earthy-musty smell (geosmin) and taste in drinking water (Wood et al. 1983) and the filamentous fungus $C$. cladosporioides. Electron microscopy demonstrated that the bacteria remained outside of $C$. cladosporioides, suggesting the possibility of an ectosymbiotic relationship of these two phylotypes in the simulated waterline biofilm community. The biofilm bacterial isolates identified appeared to be on the larger size and an explanation for this phenotypic observation may lie in bacterialfungal interactions reducing stressors in their environment and bacterial-amoebic interactions in which "if the size fits" result in them being engulfed. Thus bacteria exhibiting physiological differences in size, compared to their smaller free-living infective counterparts, may be employing this as a survival strategy.

It was of significant concern to note that L. pneumophila and $V$. vermiformis were co-habiting where amoebae were grazing on the same biofilm bacteria. Although fluorescent in-situ hybridization methodology can be used to detect/identify L. pneumophila inside amoebae (Manz et al. 1995; Grimm et al. 1998; Dutil et al. 2006), electron microscopy is also an accepted method of determining whether protozoans are acting as a carrier for Legionella (Molmerete et al. 2004, 2005). This study adopted the electron microscopy approach to distinguish whether $V$. vermiformis was able to propagate $L$. pneumophila from the environment. As no metabolically active/viable bacteria were present in the cytoplasm of these amoebae, it was concluded that L. pneumophila detected was not using this protozoan host to proliferate whilst in its natural biofilm niche. The large size of the L. pneumophila seen under the electron microscope also supports this conclusion, as it was out-with the size-range of bacteria, this amoeba choose to feed upon (Dillon et al. 2014 ${ }^{\text {b }}$ Lal et al. 2015).

\section{Conclusions}

The commercial waterline tubing developed a biofilm by day two and this was comparable to that observed in clinical waterlines, consisting of bacteria, fungi and amoebae by day 14, and Legionella was observed after 910 days. The primary biofilm culturable colonisers demonstrated a range of strategies for colonising, then adapting to nutrient poor conditions. It is accepted that this study has limitations as it only identifies and monitors the biodiversity of culturable microbes originating from the heterogeneous biofilm, on a dental 
waterline tubing lumen. However, on employing a standard molecular barcoding approach on the isolated microbes, an indication of the diversity of taxa in the biofilm was obtained, including the presence of the opportunistic pathogen L. pneumophila. An alternative approach that would have allowed identification of both culturable and non-culturable-viable taxa would have been to employ high throughput 16S rRNA gene. However, there are limitations to any technique including microbiome analysis with 16S rRNA gene sequencing. A further limitation of this study was that a non-standard protocol was used to detect Legionella. Nevertheless, the objective of the study was realised, i.e. a model was developed that was directly comparable to a clinical setting and this was "naturally" colonised by a nosocomial pathogen. The negative correlation data between CFU counts and biofilm thickness suggests a large number of dead, damaged and unculturable bacteria remain within the established biofilm. The study also identified culturable biofilm organisms that would allow biocide efficacy testing to be performed both on the in situ biofilm and on key constituent organisms. There is an ongoing need for models that will allow the development and optimization of sanitation/cleaning strategies in the clinical environment. All dental surgeries will for the foreseeable future continue to depend on dental-unit waterlines for supply of water to hand-pieces during clinical treatment. Prevention of biofilm development, in which Legionella amoebae and other pathogens can thrive is of crucial importance to ensure safety for patients and practitioners. 


\section{References}

Al Shorman H, Nabaa LA, Coulter WA, Pankhurst CL, Lynch E. 2002. Management of dental unit water lines. Dent Update. 29(6): 292-298.

American Dental Association (ADA). 2004. Statement on dental unit waterline. Available online:

\section{http://www.ada.org/1856.aspx.}

Anon. 1993. Council Directive 93/42/EEC of 14 June 1993 concerning medical devices. Offic J Eur Comm 169: 1-43.

Anon. 1996. ADA statement on dental unit water-lines. J Am Dent Assoc. 127: 185-186.

Atlas RM, Williams JF, Huntington MK. 1995. Legionella contamination of dental-unit waters. Appl Environ Microbiol. 61: 1208-1213.

Barbaree JM, Fields BS, Feeley JC, Gorman GW, Martin WT. 1986. Isolation of protozoa from water associated with a Legionellosis outbreak and demonstration of intracellular multiplication of Legionella pneumophilia. Appl Environ Microbiol 51: 422-424.

Barbeau J, Buhler T. 2001. Biofilms augment the number of free-living amoebae in dental unit waterlines. Res Microbiol. 52(8): 753-760.

Barbot V, Robert A, Rodier MH, Imbert C. 2012. Update on infectious risks associated with dental unit waterlines. FEMS Immunol Med Microbiol. 65(2): 196-204.

Blake GC. 1963. The Incidence and Control of Bacterial Infection in Dental Spray Reservoirs. Brit Dent J. 115(10):413-416.

Chate RA. 2010. An audit improves the quality of water within the dental unit water lines of general dental practices across the East of England. Br Dent J. 209(7): E11.

Costa D, Girardot M, Bertaux J, Verdon J, Imbert C. 2016. Efficacy of dental unit waterlines disinfectants on a polymicrobial biofilm. Water Res. 91: 38-44.

Dennison, S.R., Morton, L.H.G, Shorrocks, A.J, Harris, F. \& Phoenix, D.A. (2009) A study on the interactions of Aurein 2.5 with bacterial membranes. Colloids and Surfaces B: Biointerfaces. 68(2): 225- 
Dillon A, Achilles-Day UE, Singhrao SK, Pearce M, Morton LG, Crean S. 2014ª . Biocide sensitivity of Vermamoeba vermiformis isolated from dental-unit-waterline systems. Int Biodeterioration Biodegrad. 88: 97-105.

Dillon A, Singhrao SK, Achilles-Day UE, Pearce M, Morton LG, Crean S. 2014 ${ }^{\mathrm{b}}$. Vermamoeba vermiformis does not propagate Legionella pneumophila subsp. pascullei in a simulated laboratory dentalunit waterline system. Int Biodeterioration Biodegrad. 90: 1-7.

Ditommaso S, Giacomuzzi M, Ricciardi E, Zotti CM. 2016. Efficacy of a low dose of hydrogen peroxide (peroxy $\mathrm{Ag}^{+}$) for continuous treatment of dental unit water lines: Challenge test with Legionella pneumophila serogroup 1 in a simulated dental unit waterline. Int J Environ Res Public Health. 13(2): 211.

Donlan RM, Costerton JW. 2002. Biofilms: survival mechanisms of clinically relevant microorganisms. Clin Microbiol Rev. 15: 167-193.

D’Ovidio C, Carnevale A, Pantaleone G, Piattelli A, Di Bonaventura G. 2011. First report of an acute purulent maxillary sinusitis caused by Pseudomonas aeruginosa secondary to dental implant placement in an immunocompetent patient. Brit Dent J. 211: 205-207.

Dutil S, Tessier S, Veillette M, Laflamme C, Meriaux A, Leduc A, Barbeau J, Duchaine C (2006) Detection of Legionella spp. by fluorescent in situ hybridization in dental unit waterlines. J Appl Microbiol. 100(5): 955-963.

Fernandes C, Rainey FA, Nobre MF, Pinhal I, Folhas F, Da Costa MS. 2005. Herminiimonas fonticola gen. nov., sp. nov., a Betaproteobacterium isolated from a source of bottled mineral water. Syst Appl Microbiol. 28(7): 596-603.

Fraser DW, Tsai TR, Orenstein W, Parkin WE, Beecham HJ, Sharrar RG, Harris J, Mallison GF, Martin SM, McDade JE, Shepard CC, Brachman PS. 1977. Legionnaires' disease: description of an epidemic of pneumonia. N Engl J Med. 297: 1189-1197.

Furutani M, Suzuki T, Ishihara H, Hashimoto H, Kunoh H, Takada J. 2012. Assemblage of bacterial saccharic microfibrils in sheath skeleton formed by cultured Leptothrix sp. strain OUMS1. J Marine Sci Res Develop. 2013. 
Legionella pneumophila: construction of a new 16S rRNA-targeted oligonucleotide probe. Appl Environ

\section{Microbiol. 64(7): 2686-2690.}

Hall-Stoodley L, Keevil CW, Lappin-Scott HM. 1998. Mycobacterium fortuitum and Mycobacterium chelonae biofilm formation under high and low nutrient conditions. J Appl Microbiol. 85(S1).

John GH, Noel RK, Peter HAS, James TS, Stanley TW. 1993. Bergey's Manual of Determinative Bacteriology. ISBN: 0-683-00603-7, Williams \& Wilkins, USA.

Johnson JR, Roberts PL, Olsen RJ, Moyer KA, Stamm WE. 1990. Prevention of catheter-associated urinary tract infection with a silver oxide-coated urinary catheter: clinical and microbiologic correlates. J Infect Dis. 162(5): 1145-1150.

Kadaifciler DG, Cotuk A. 2014. Microbial contamination of dental unit waterlines and effect on quality of indoor air. Environ Monit Assess. 186(6): 3431-3444.

Kilb B, Lange B, Schaule G, Flemming HC, Wingender J. 2003. Contamination of drinking water by coliforms from biofilms grown on rubber-coated valves. Int J Hyg Envir Heal. 206(6): 563-573.

Kohn W, Collins A, Cleveland J, Harte J, Eklund K, Malvitz D. 2003. Guidelines for infection control in dental health-care settings. MMWR. Recommendations And Reports / Centers for Disease Control [serial online] 52(RR-17): 1-61. http://www.cdc.gov/mmwr/preview/mmwrhtml/rr5217a1.htm.

Kumar S, Atray D, Paiwail D, Balasubramanyam G, Duraiswamy P, Kulkarni S. 2010. Dental unit waterlines: source of contamination and cross infection. J Hosp Infect. 74: 99-111.

Lal S, Singhrao SK, Achilles-Day UE, Morton LG, Pearce M, Crean S. 2015. Risk Assessment for the spread of Serratia marcescens within dental-unit waterline systems using Vermamoeba vermiformis. Curr Microbiol. 71(4): 434-442.

Lal S. 2016. Investigating contamination of dental-unit waterlines and microbial ecology. $\mathrm{PhD}$ thesis.

Lang E, Swiderski J, Stackebrandt E, Schumann P, Spröer C, Sahin N. 2007. Herminiimonas saxobsidens sp. nov., isolated from a lichen-colonized rock. Int J Syst Evol Microbiol. 57(11): 2618-2622. 
$\underline{\text { situ identification of Legionellaceae using 16S rRNA-targeted oligonucleotide probes and confocal laser }}$

scanning microscopy. Microbiology. 141(1): 29-39.

Marin B, Palm A, Klingberg M, Melkonian M. 2003. Phylogeny and taxonomic revision of plastidcontaining euglenophytes based on SSU rDNA sequence comparisons and synapomorphic signatures in the SSU rRNA secondary structure. Protist. 154: 99-145.

Martin M. 1987. The significance of the bacterial contamination of dental unit water systems. Brit Dent J. 163: 152-154.

Michel R, Just HM. 1984. Acanthamoebae, Naegleria and other free-living Amoebae in cooling and rinsing water of dental treatment units. Zentralblatt Fur Bakteriologie Mikrobiologie und Hygiene Series B. 179: $56-72$.

\section{Molmeret M, Horn M, Wagner M, Santic M, Kwaik YA. 2005. Amoebae as training grounds for} intracellular bacterial pathogens. Appl Environ Microbiol. 71: 20-28.

Molmeret M, Bitar DM, Han L, Kwaik YA. 2004. Disruption of the phagosomal membrane and egress of Legionella pneumophila into the cytoplasm during the last stages of intracellular infection of macrophages and Acanthamoeba polyphaga. Infect Immun. 72(7): 4040-4051.

Nakajima-Kambe T, Onuma F, Kimpara N, Nakahara T. 1995. Isolation and characterization of a bacterium which utilizes polyester polyurethane as a sole carbon and nitrogen source. FEMS Microbiol Lett. 129(1): 39-42.

Onions AHS, Allsopp D, Eggins HOW. 1991. Smith's Introduction to Industrial Mycology. ISBN: 9780521427821, Cambridge University Press.

Palleroni NJ. 1989. Pseudomonads In: Practical handbook of Microbiology by W. M. O’Leary, CRC London Press. 55-66.

Paster BJ, Boches S, Galvin J, Ericson RE, Lau C, Levanos VA, Sahasrabudhe A, Dewhirst FE. 2001. Bacterial diversity in human subgingival plaque. J Bacteriol. 188: 3770-3783. 
the scientific argument. Int Dent J. 48: 359-368.

Proft T, Baker EN. 2009. Pili in Gram-negative and Gram-positive bacteria—structure, assembly and their role in disease. Cell Mol life Sci. 66(4): 613-635.

Reasoner DJ, Geldreich EE. 1979. A new medium for the enumeration and subculture of bacteria from potable water. Abstracts of the Annual Meeting of the American Society for Microbiology 79th Meeting, Paper No. N7.

Reasoner DJ, Geldreich EE. 1985. A new medium for the enumeration and subculture of bacteria from potable water. Appl \& Environ Microbiol. 49(1): 1-7.

Ricci ML, Fontana S, Pinci F, Fiumana E, Pedna MF, Farolfi P, Sabattini MA, Scaturro M. 2012. Pneumonia associated with a dental unit waterline. The Lancet. 379: 684.

Rittenhouse HG, McFadden BA, Shumway LK, Heptinstali J. 1973. Cell surface protein of Pseudomonas (Hydrogenomonas) facilis. J Bacteriol. 115(1): 330-340.

Rowbotham TJ_ 1986. Current views of the relationships between amoebae, Legionella and man. Isr. J Med Sci. 22: 678-689.

Spratt DA, Latif J, Montebugnoli LL, Wilson M. 2004. In vitro modelling of dental water line contamination and decontamination. FEMS Microbiol Lett. 235(2): 363-367.

Stackebrandt E, Goebel BM. 1994. Taxonomic note: a place for DNA-DNA reassociation and 16S rRNA sequence analysis in the present species definition in bacteriology. Int J Syst Evol Micr. 44(4): 846849.

$\underline{\text { Szymanska J, Sitkowska J, Dutkiewicz J. 2008. Microbial contamination of dental unit waterlines. }}$ Ann Agric Environ Med. 15: 173-179.

Tall BD, Williams HN, George KS, Gray RT, Walch M. 1995. Bacterial succession within a biofilm in water supply lines of dental air-water syringes. Can J Microbiol. 41(7): 647-654.

Tyndall RL, Domingue EL. 1982. Cocultivation of Legionella pneumophila and free living amoebae. Appl Environ Microbiol_. 44: 954-959. 
Works Assoc. 57-65.

Wadowsky RM, Wilson TM, Kapp NJ, West AJ, Kuchta JM, States SJ, Dowling JN, Yee RB. 1991. Multiplication of Legionella spp. in tap water containing Hartmannella vermiformis. Appl Environ Microbiol. 57: 1950-1955.

Williams HN, Kelley J, Folineo D, Williams GC, Hawley CL, Sibiski J. 1994. Assessing microbial contamination in clean water dental units and compliance_with disinfection protocol. J Am Dent Assoc. 125: 1205-1211.

Wood S, Williams ST, White WR. 1983. Microbes as a source of earthy flavours in potable water. A review. Int Biodeterioration Biodegrad. (3-4): 83-97.

\section{Legends}

Figure 1. A simulated laboratory dental-unit waterline system adapted from Spratt et al. (2004) and Dillon et al. $\left(2014^{\mathrm{a}}\right)$. One half represents the day model showing fresh water from tap going into the reservoir during the daytime. A peristaltic pump circulates the water (in the direction of the arrow) at defined rate of exchange (see main text). The tube sections taken for biofilm analyses are indicated for the first 4 cuts and the output water analysed for CFU counts. The dotted line separates the night time and weekend model. The tubing from tap to reservoir was attached via a connector to the output water tubing at end of each working day.

Figure 2. Planktonic bacterial counts from the simulated waterlines output water and tap water (source), A) for first three days after installation of simulated waterlines. Difference in CFU ml ${ }^{-1}$ count was statistically significant $(p=0.0001)$, B) for 183 days. C) Live/dead cell assay $\underline{\text { A) }}$ untreated smear showing no autofluorescing cells, $\underline{B}$ ) formalin treated cells having taken up Propidium Iodide (PI), $\underline{\text { C) }} \underline{\text { Smear showing }}$ cells with damaged membrane have taken up PI and other possibly dead cells protected by extracellular matix coating failed to take up PI (black spaces). 
Figure 3. SEM of the biofilm within the tubing lumen. A) No microbial growth was observed on new tubing with antimicrobial coating before installation, B) Few colonies observed after 5 days (circles), C) higher

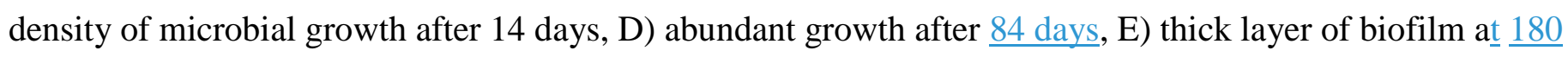
days, F) multilayers of biofilm after 910 days.

Figure 4. SEM micrographs of sequence of biofilm flora colonisation on the lumen of waterline tubing, A) no microbial growth after 1st day, note the rough luminal surface of an antimicrobial coating, B) rod shaped bacteria from 2nd to 5th day (Box), C) cocci and rod shaped bacteria after 6 days, D) cocci and rods with exopolysaccharide matrix after 6 days, E) spiral shaped bacteria (possibly an Actinomycete spore) after 8 days (arrow), E1 insert) showing image of spiral shaped bacterium, F) long curved rod shaped bacteria after 9 days, G) long spiral shaped bacteria noted after 3 months (arrow), H) fungal hypha imaged after $1 \underline{80 \text { days }}$ (box), I) fully established biofilm with bacteria, fungi and amoeba (box) after 910 days.

Figure $\underline{5}$. TEM micrographs showing an amoebal trophozoite of $V$. vermiformis with pseudopodia and the hyaloplasm around the periphery of the cell (A), a nucleus and food vacuole visible in some trophozoites (B). 